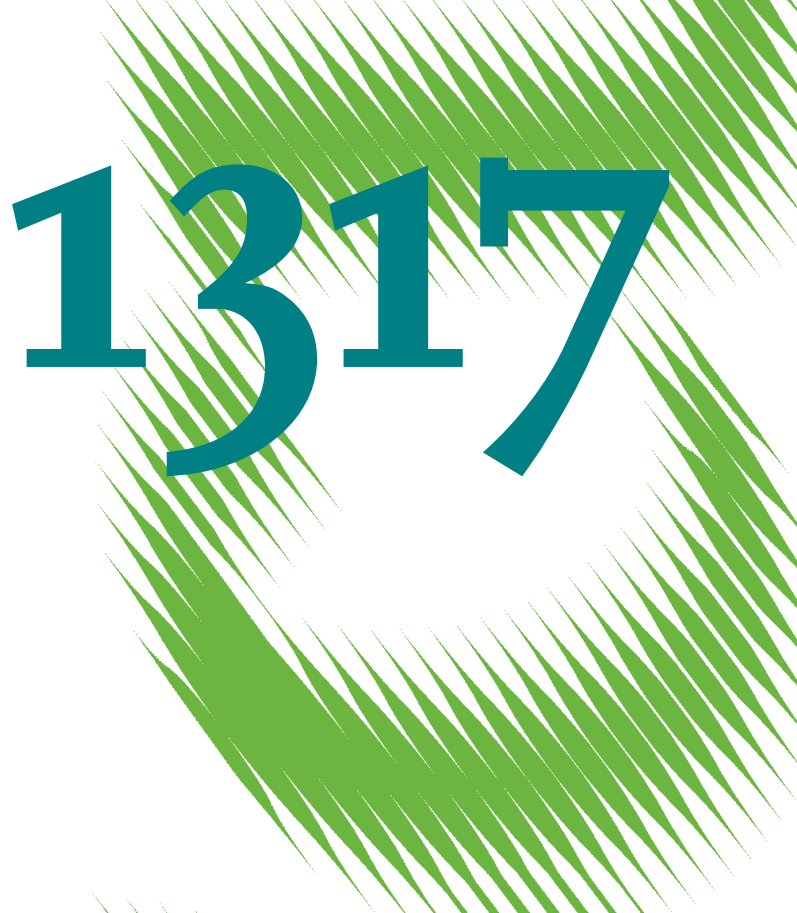

Combining Energy Networks

The Impact of Europe's Natural Gas Network on Electricity Markets until 2050 
Opinions expressed in this paper are those of the author(s) and do not necessarily reflect views of the institute.

IMPRESSUM

(C) DIW Berlin, 2013

DIW Berlin

German Institute for Economic Research

Mohrenstr. 58

10117 Berlin

Tel. $+49(30) 89789-0$

Fax +49 (30) $89789-200$

http://www.diw.de

ISSN print edition $1433-0210$

ISSN electronic edition 1619-4535

Papers can be downloaded free of charge from the DIW Berlin website:

http://www.diw.de/discussionpapers

Discussion Papers of DIW Berlin are indexed in RePEc and SSRN:

http://ideas.repec.org/s/diw/diwwpp.html

http://www.ssrn.com/link/DIW-Berlin-German-Inst-Econ-Res.html 


\title{
Combining Energy Networks: \\ The Impact of Europe's Natural Gas Network on Electricity Markets \\ until 2050
}

\author{
Jan Abrell ${ }^{a}$, Clemens Gerbaulet ${ }^{b, c}$, Franziska Holz ${ }^{c}$, Casimir Lorenz ${ }^{b}$, \\ Hannes Weigt*
}

\section{Abstract:}

The interdependence of electricity and natural gas is becoming a major energy policy and regulatory issue in all jurisdictions around the world. The increased role of gas fired plants in renewable-based electricity markets and the dependence on gas imports make this issue particular striking for the European energy market. In this paper we provide a comprehensive combined analysis of electricity and natural gas infrastructure with an applied focus. We analyze different scenarios of the long-term European decarbonization pathways sketched out by the Energy Roadmap 2050, and identify criteria related to electricity and/or natural gas infrastructure and the interrelation between both markets.

Keywords: Europe, electricity markets, natural gas markets, networks

JEL-code: $\quad$ L94, L95, C61

* Corresponding author: Forschungsstelle Nachhaltige Energie- und Wasserversorgung (FoNEW), University of Basel, hannes.weigt@unibas.ch

${ }^{a}$ CEPE, ETH Zurich, ${ }^{b}$ WIP, TU Berlin, ${ }^{c}$ DIW Berlin

\section{Acknowledgements:}

We thank John Liao for research assistance, Jonas Egerer for providing electricity data and Christian von Hirschhausen as well as the rest of the EMF 28 group for helpful discussions of the results. All remaining errors are ours. 


\section{Introduction}

When both the German and the French energy systems were close to a breakdown on February $9^{\text {th }}$, 2012, energy policymakers and regulators „discovered“ that electricity networks and the natural gas infrastructure, which had been treated independently from each other for the last decades, are closely interconnected. A cold spell in continental Europe sent electricity demand in France to a long-time high of $100 \mathrm{GW}$. In the meantime, six German nuclear power plants that previously assured cheap electricity exports to France had been shut down following the moratorium on nuclear power after the Fukushima accident in March 2011. Gas-fired combined cycle plants in the South of Germany could not substitute for the loss of power from the nuclear plants due to a lack of access to gas pipeline capacity. At the same time, plenty of natural gas was transported from Austria and South Germany to Italy (EC, 2012). While rolling blackouts could be avoided due to active demand management by the French operators, the issue of electricity-natural gas interdependence was launched and led to a major enquiry by the European Commission, with concrete regulatory action most likely upcoming.

The issue of electricity-natural gas interdependence it not specific to the one case mentioned and is becoming a major energy policy and regulatory issue in all jurisdictions around the world undergoing the transformation to a lower-carbon and/or renewables-based energy system. Naturally the issue rose to top priority in Japan after the closing down of nuclear power in 2011 and likewise advanced to center stage in North America following the „shale gas revolution“, e.g. in PJM (Sotkiewicz, 2012). Furthermore, the developments of the Arab Spring and the recurrent disputes between Russia and its gas transit countries Belarus and the Ukraine highlighted the issue of supply security of the import dependent European Union.

Some countries and regions within the European Union currently are dependent on a very small number of suppliers, which makes them vulnerable to supply disruptions even if they are temporary. The South European countries (Italy and increasingly Spain) strongly depend on pipeline imports from North Africa (Algeria, Libya) and use liquefied natural gas (LNG) to diversify their supplies and respond to short-term demand spikes. The Central and South East European countries import almost exclusively from Russia and the current network topology does not allow them to quickly change this import pattern. For this region, storage and especially reverse flow capacities (to import from the West to the East, opposite the traditional direction from the East / Russia to the West) are put forward as remedies to increase their security of supply, in addition to increasing the number of import routes. The European Commission has stipulated these measures in its Supply Security Directive (EU, 2004), 
which also guided its decisions on the TEN-E and EEPR project support $(E U, 2006,2009)$ and are picked up by the Ten-Year Network Development Plans of the natural gas transmission system operators in Europe (e.g. ENTSO-G, 2011).

Also, the continuing deployment of intermittent capacities of renewable energy sources (RES) in the electricity sector is supposed to increase the role of natural gas as fuel option. The European Commission (EC) states in the EU Energy Roadmap 2050 that gas "will be critical for the transformation of the energy system" as electricity production from gas has the lowest emissions compared to other fossil-based technologies and will help reach the climate goals (EC, 2011a). Although the production of electricity from gas is projected to decline in the future as the influence of renewable energy sources increases, gas is assumed to be the major fossil fuel for electricity generation in the coming years (EC, 2011b).

Summarizing all those relevant aspects in both markets, it becomes evident that a combined assessment is needed to derive solid recommendations about the future development of the European energy markets. However, most model-based analyses thus far have only focused on a single sector. A large stream of literature has addressed the development of electricity markets and networks in the wake of an increased share of RES (e.g. Neuhoff et al., 2008; Egerer et al., 2012). Studies like ECF (2011), Haller et al. (2012) and SRU (2010) determine possible development paths for the European electricity system. Investment needs in grid and generation infrastructure, based on renewable targets and potentials, is determined mostly in a cost-minimizing or welfare-maximizing way. In most models that determine European grid development, the electricity grid infrastructure is mostly modeled with a low spatial resolution and electricity-specifics, like loop flows, are not taken into account. Several papers address the market structure and development of the European and global natural gas markets (e.g. Egging et al., 2008, 2010). Finally, large scale energy system and macroeconomic models as well as technically-oriented simulation and optimization models cover the interrelation between fuel markets and the economy as a whole, but in an aggregated manner. These models often lack details of the transmission system (e.g. Capros et al., 1997; Paltsev et al., 2005; Möst and Perlwitz, 2009; IPTS, 2010; Capros, 2010),

Literature relating to an integrated analysis of electricity and natural gas network markets is scarce and so far mostly addresses methodological and technical aspects of how to combine both markets in a model framework with small test cases to highlight the applicability or derive stylized insights. For example, Unsihuay et al. (2007) model an integrated gas-electricity system with the goal of minimizing the short-term system operation cost by examining a test case network based on the Belgian gas grid. 
Another approach is the hub system applied by Arnold and Anderson (2008) which decomposes a power flow optimization problem for gas and electricity to model larger applications. Abrell and Weigt (2012) combine both markets within a partial equilibrium representation. Their model is applied to a European test case and shows that upstream and downstream influences between these sectors exist both in terms of price and quantity interactions. Furthermore, they show that effects and interactions of changes in the respective markets are not geographically limited but extend beyond the point of disturbance due to the loop-flow characteristics in the electricity market.

In this paper, we provide a comprehensive combined analysis of electricity and natural gas infrastructure issues with an applied focus and a complete dataset covering the European networks. Following the approach of Abrell and Weigt (2012) of combining both markets in an equilibrium setting, we analyze different scenarios of the long-term European decarbonization pathways sketched out by the Energy Roadmap 2050 and by the EMF28 effort on "The Effects of Technology Choices on EU Climate Policy". ${ }^{1}$ We identify critical issues related to electricity and/or natural gas infrastructure and the interrelation between both markets. The next section describes the initial model used and the extensions that have been made to address certain scenarios for the European decarbonization process. The network topology of the electric and natural gas infrastructure, respectively, the data and other assumptions are also discussed. Section 3 describes the results of the basic model runs, section 4 discusses the effects of different load and generation conditions on the electricity market, section 5 discusses the impact of gas market disruptions on the electricity system, and section 6 summarizes and concludes.

\section{Model and Parameterization}

\subsection{The model}

The model in this paper allows for a combined natural gas and electricity sector representation, both taking into account the respective sector's transmission grid and how they can be run independently of one another or in a combined manner (Figure 1). The natural gas model, which is shown on the left hand side of Figure 1, depicts pipelines and LNG routes as a multi-commodity network. The arcs in the pipeline network are directed, i.e. the natural gas flows in a predetermined direction given by the

\footnotetext{
${ }^{1}$ http://emf.stanford.edu/research/emf_28_the_effects_of_technology_choices_on_eu_climate_policy/
} 
compressor stations in the pipeline network. Possible LNG routes are implicitly defined via exogenously given export (liquefaction) and import (regasification) capacities. Natural gas producers offer the extracted gas at the supply market to either an LNG operator or a trader, in a similar setting than in Egging (2010). While LNG traders sell the gas on the destination market to a trader, traders demand the services of transporting the gas to the final demand from the pipeline operator. Final consumers demand the gas at that market and pay a price which includes the transport fees. If the natural gas model is run independently from the electricity model, final demand includes the demand by the electricity generators using natural gas fired power plants.

The electricity model, which is depicted on the right side of Figure 1, includes the transmission grid using a DC-loadflow approach (Schweppe et al., 1988, Leuthold et al., 2012) and a market hub system (Hobbs, 2001). Electricity generators sell electricity to network operators who serve final consumers. As long as the electricity model is used independently of the natural gas model, all fuel prices are exogenous.

The two models are combined by including the fuel linkage: the demand of natural gas fired power plants becomes an endogenous variable in the natural gas model and the natural gas price an endogenous variable in the electricity model.

A complete mathematical model description is given in Abrell and Weigt (2012). The approach used here is static in the sense that we solve the models for one representative hour and storage is neither included in the electricity nor in the natural gas market. Furthermore, we assume perfect competition in all markets and complete information of all agents about all variables, i.e. the model is deterministic. Finally, the cross-price elasticity of natural gas and electricity final demand is assumed to be zero, i.e. the final demand for the energy commodities is independent. The two sub-models, as well as the combined one, are formulated as Mixed Complementarity Problems in GAMS (Brooke et al., 2008) and solved using the PATH solver (Ferris and Munson, 2000). 
Figure 1: Model overview

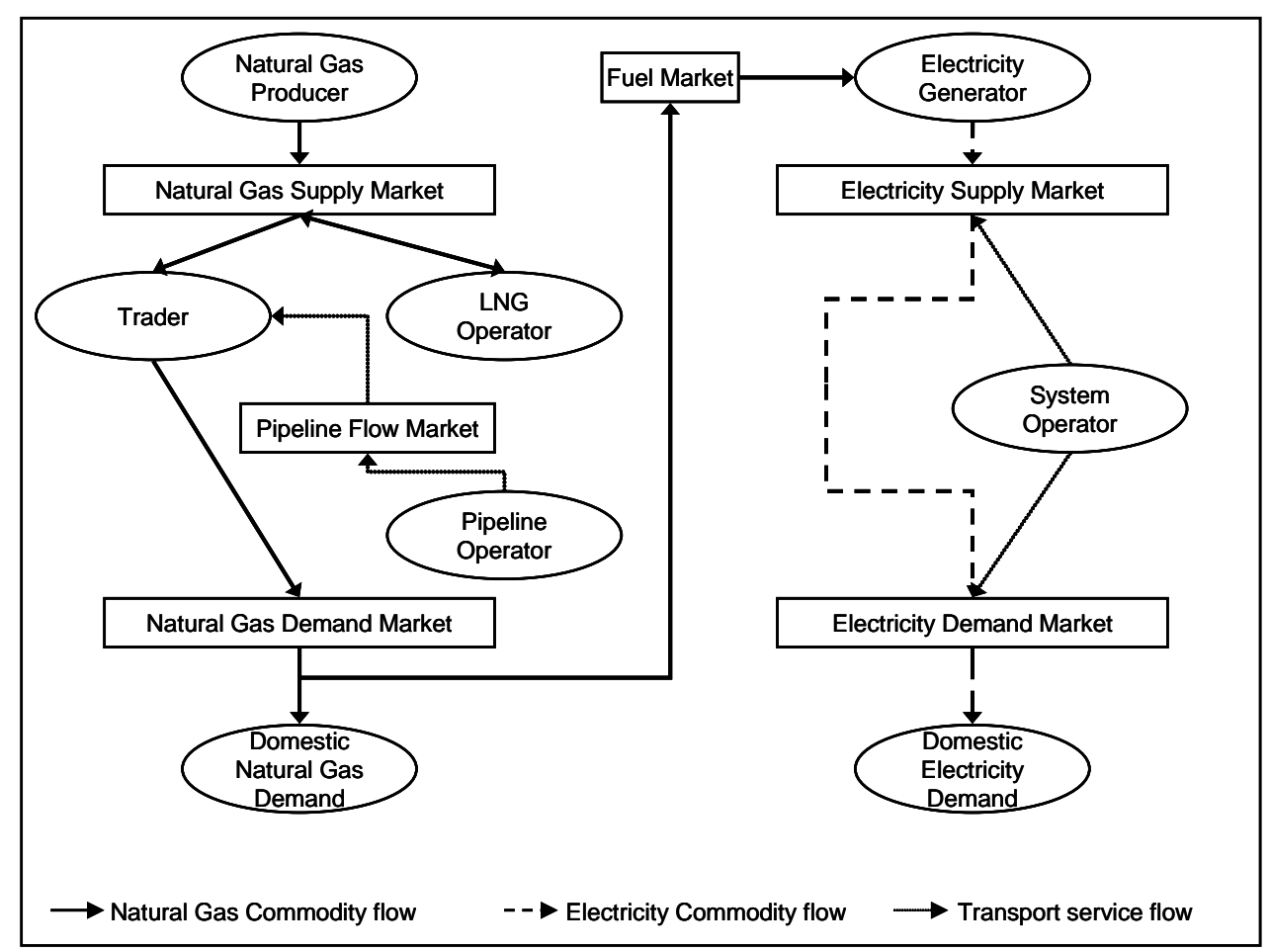

\subsection{Data}

We combine the natural gas and the electricity sector data for the base year 2010 and for the years $2020,2030,2040$, and 2050 . Hourly data is used for a representative demand hour and the data input then varies in each of the scenarios.

The natural gas data contains all European countries with one node per country and some more nonEU countries that export natural gas to Europe. The nodes are linked with each other in a pipeline network and a virtual network of liquefied natural gas (LNG) trading routes between liquefiers (exporters) and regasifiers (importers). The pipeline network and LNG import capacities are based on 2010 data by the European transmission system operators (ENTSO-G, 2010). For the periods beyond 2010, the 2012 capacity data by ENSO-G (ENTSO-G, 2012) and the Ten-Year Network Development Plan (TYNDP, ENTSO-G, 2011) were the basis to determine the capacities in place in the future. Liquefaction capacities are given by the IEA (2012a) for 2010 and are derived from the IEA (2012b) for the periods thereafter. The related costs and losses parameters for pipelines, liquefaction, and regasification are based on the World Gas Model (Egging et al., 2010). PRIMES results for the Energy Modeling Forum 28 (EMF28) and the Energy Roadmap 2050 (EC, 2011) provide final demand and demand by the 
electricity sector for natural gas, as well as reference prices for all periods. This yearly data for all EU27 countries was scaled down to hourly data.

The electricity model specifies the characteristics of generation technologies in terms of the heat efficiency, emission coefficients and installed capacity for each technology at each node in the electricity grid. Furthermore, country-specific prices for the primary energy carriers, nuclear, lignite, hard coal and biomass, given by the PRIMES model results are used as fuel price inputs. The transmission grid is shown in Figure 2 and is based on the ENTSO-E Grid Map 2011 (ENTSO-E, 2011) and the grid extension projects described in the 2012 version of the ten-year network development plan (TYNDP) (ENTSO-E, 2012a). The grid for 2010 is taken from the ENTSO-E Grid Map 2011 without new built or planned projects. In the grid for 2020 all planned projects, as well as the mid-term grid extension projects (2012-2016) of the TYNDP, are added to the grid. The grids for 2030 and the following time steps additionally consist of the long-term TYNDP projects of pan-European significance. The grid structure in Figure 2 shows the 2030 AC-grid. For the model calculations, the electricity grid is aggregated into 47 zones. Each zone consists of one or more NUTS1 (Nomenclature des unités territoriales statistique) zones.

Available technologies are clustered according to type. ${ }^{2}$ The technology characteristics of the different plant types (efficiency, availability, installed capacity) are based on the PRIMES results of the EMF28 scenarios. The spatial distribution towards the different network zones is based on the Platts Database (Platts, 2011), from which each power plant's geo-coordinates were determined. These power plant capacities were aggregated to the zones in the model. This allows for a regional allocation and scaling of the generation capacities reported for each country by the PRIMES model for each scenario and time period. Based on the technical potential for wind and solar provided by ESPON (2010), the national RES capacities provided by PRIMES are spatially allocated to the NUTS1 zones.

The demand for electricity represents each country's average winter demand. The yearly demand for electricity is taken from PRIMES and scaled with a summer/winter demand ratio determined from historical demand values obtained from ENTSO-E (ENTSO-E, 2012b). These national values are spatially allocated to NUTS1 zones based on population share. For countries not reported by PRIMES (like Switzerland and Norway), assumptions regarding the development of renewable capacity expansion

\footnotetext{
${ }^{2}$ Those are: Nuclear, Lignite, Lignite with CCS, Coal, Coal with CCS, Gas Combined Cycle, Gas Combined Cycle with CCS, Gas Turbines, Gas Turbines with CCS, Hydropower, Biomass, Photovoltaic (PV), Concentrated Solar Power (CSP), Wind Onshore and Wind Offshore
} 
and electricity demand have been made based on renewable availability and the development of neighboring countries.

Figure 2: Stylized natural gas network (left) and electricity network with zones (right)
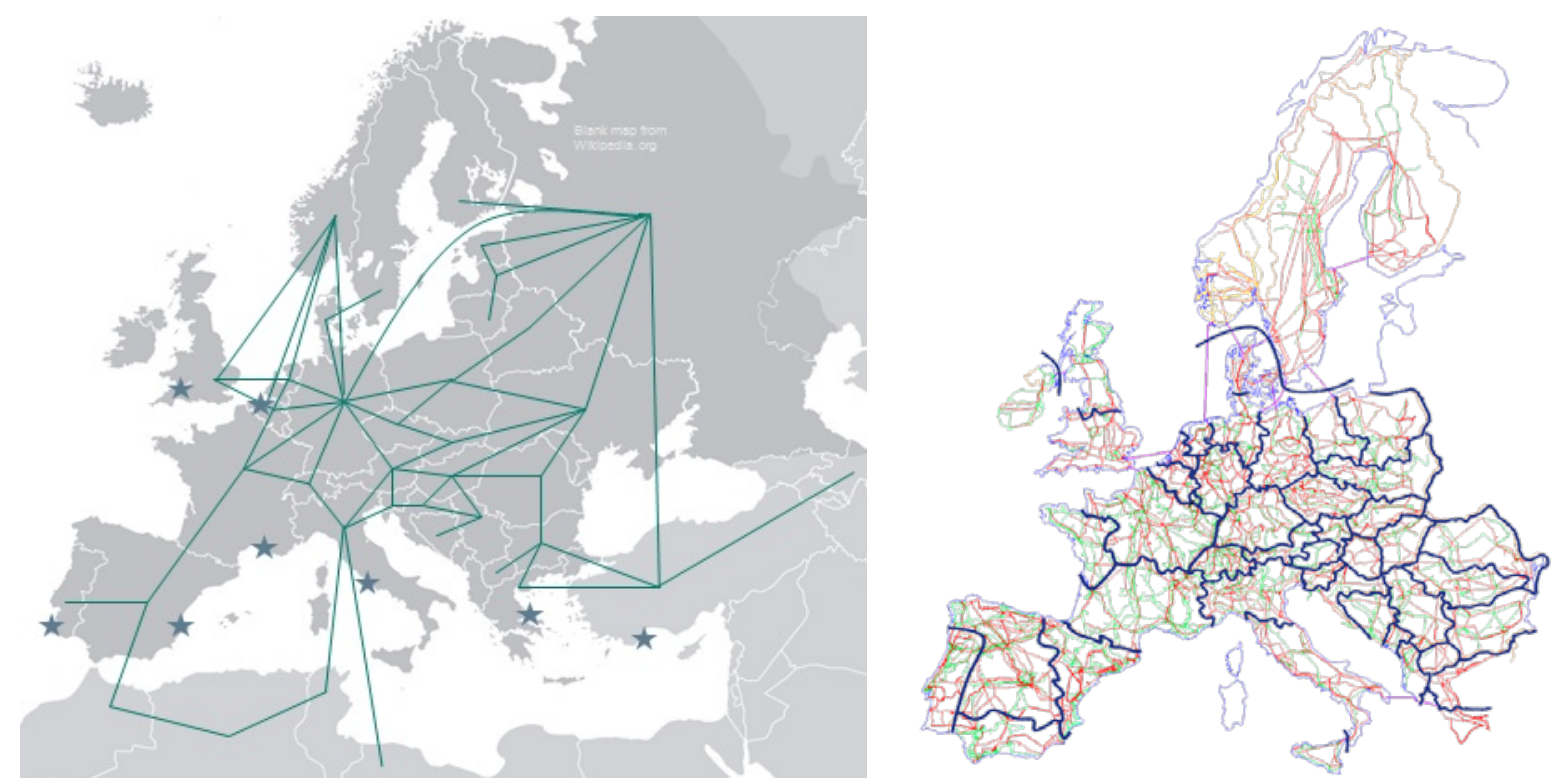

\section{Basic Result Overview}

In a first step, we provide an overview on the development of the European natural gas and electricity markets until 2050. We analyze three of the EMF 28 scenarios in detail: ${ }^{3}$

- $40 \% D E F$ : representing a "moderate policy" scenario with all default technology options available, the EU`s 2020 targets in place, and a European $40 \% \mathrm{CO}_{2}$ emission reduction target for 2050 ,

- $80 \% D E F$ : similar to the basic setting of $40 \% \mathrm{DEF}$ but with a more stringent $\mathrm{CO}_{2}$ emission target of $80 \%$ until 2050 for Europe,

- $80 \%$ GREEN: same target as the $80 \%$ DEF setting but with a higher share of "green" RES generation, stronger energy efficiency development and constrained usage of CCS and nuclear.

The selected scenarios cover a diverse mix of potential developments and thus the simulated market results span a broad range. As the model is time-static, utilizes a reference hour approach, neglects

\footnotetext{
${ }^{3}$ An overview of the aggregated results is provided in the Appendix.
} 
global gas market interactions, and assumes perfectly competitive markets, the obtained results represent a lower boundary on expected market developments.

Although the development paths are different, there are still some common trends for all scenarios: First, the market situation in 2010 has a similar pattern in all three settings. ${ }^{4}$ In the electricity market, there is a price separation of the Iberian Peninsula from the rest of Europe, a relatively uniform price level in Eastern Europe, a slightly higher price level in Central Europe and price spikes in Italy. Network congestion occurs mainly at the French and German borders as well as on lines towards Italy. The average generation mix consists of nuclear, coal and RES (including hydro) to equal shares and about $10 \%$ of natural gas fired plants (Table 2). In the natural gas market, the absolute price level is different in the $40 \%$ DEF scenario due to the lower reference prices in 2010 but the spatial price and demand pattern is similar to the $80 \%$ DEF and $80 \%$ GREEN cases: Central Europe has a uniform price level supplied by Russian imports and North Sea gas from Norway and the Netherlands, South East Europe has a lower price level due to cheap Russian supplies and limited interconnection to Central Europe, and the Iberian Peninsula is decoupled and supplied by North African gas and LNG imports.

The second common result over all scenarios is the general development of the natural gas market segmentation. Given the Nordstream connection from Russia to Germany, further extensions according to the TYNDP within Europe, planned LNG extensions, and the assumed perfectly competitive market setting, network congestion plays only a minor role in the future European gas market and consequently we observe a relatively uniform price level across Europe for all cases. The price differences between the 40\%DEF and 80\%DEF/GREEN scenarios (Figure 3) are based on the different underlying reference prices. However, the demand development and the resulting production patterns differ greatly between the scenarios.

For the electricity market, the projected extensions by ENTSOE`s TYNDP also lead to a price convergence across Europe on average but the development varies even more by scenario than in the natural gas market. This is based on the different RES and nuclear assumptions that translate into different dispatch patterns (Table 2). ${ }^{5}$

The main differences of the three scenarios stem from the underlying reference price levels. In the $40 \% \mathrm{DEF}$ setting, future fuel and electricity price assumptions are the highest, which translates into the

\footnotetext{
${ }^{4}$ Note that the model uses the EMF28 PRIMES results for 2010 and not the observed market outcomes.

${ }^{5}$ A final similarity between all scenarios is the development of CCS generation. Due to the underlying emission price assumptions fossil generation without CCS has a severe cost disadvantage from 2030 onward and consequently is phased out until 2050 as more CCS plants come online.
} 
model results. The $40 \% \mathrm{DEF}$ case shows both the highest absolute price levels of all cases and the only scenario with a steady price increase for both electricity and natural gas (Figure 3). The 80\%DEF/GREEN cases share the same underlying fuel price assumptions and also show a similar price development, particularly in the natural gas market. The electricity price development shows a curved pattern with a decline towards 2050. From 2030 onward, the 80\%DEF price is above the $80 \%$ GREEN price due to the different dispatch of RES and nuclear plants. In the 80\%GREEN setting, nuclear plants phase out faster while the RES share strongly increases. The price decreasing effect of RES generation with low marginal costs leads to an electricity price decline to the lowest absolute levels (Figure 3). ${ }^{6}$ However, as RES is not necessary located where the phased out nuclear plants were located, this increases transmission requirements which is evident by the high congestion rents in the 80\%GREEN 2050 case (Table 2).

The lower prices in the $80 \% \mathrm{DEF} / \mathrm{GREEN}$ cases, compared to the $40 \% \mathrm{DEF}$ scenario, also translate into the demand level. Whereas the underlying reference demand for electricity declines in the former two cases and increases in the 40\%DEF scenario (see Section 2.2), the model runs show a different demand development (Table 2). While the 40\%DEF demand still grows over time, the increase is significantly higher in the $80 \% \mathrm{DEF} / \mathrm{GREEN}$ scenarios. This is a result of the assumed demand elasticity and the obtained market prices. The higher share of RES generation and the lower reliance on conventional power plants in the $80 \% \mathrm{DEF} / \mathrm{GREEN}$ scenarios lead to a low electricity price level and allow a higher satisfied demand than in the 40\%DEF case.

The usage of gas for electricity generation differs over time and the scenarios. In all cases, the highest share is obtained in 2020. This is a result of low natural gas prices coupled with the emission price that reduces the competiveness of coal plants. At the same time, RES and CCS capacities are not yet sufficient to fully cover the difference. From then on the share of gas plants declines to almost $0 \%$ in 2050 in the $40 \%$ DEF and $80 \%$ GREEN scenarios and remains relatively stable with $10 \%$ in the $80 \%$ DEF scenario. Despite the similar developments of the $40 \%$ DEF and $80 \%$ GREEN scenarios, the underlying reasons are strikingly different. In the 40\%DEF case, nuclear and coal CCS plants continue to supply about $40 \%$ of electricity generation while the increased RES share is compensated by a decrease in gas fired generation. In the $80 \%$ GREEN scenario, nuclear and fossil generation are phased out and RES generation covers more than $90 \%$ of the demand in 2050 .

\footnotetext{
${ }^{6}$ The model results represent short-run marginal costs and thus do not account for investment cost recovery.
} 
In the $80 \%$ DEF scenario, the situation is more diverse. While the deployment of RES and the phase out of nuclear plants are faster than in the 40\%DEF setting, they are still slower than in the 80\%GREEN scenario. Thus, fossil generation still plays an important role in satisfying electricity demand. However, due to the lower natural gas prices compared to the $40 \%$ DEF scenario (Table 1 ), gas fired CCS plants have a price advantage compared to coal CCS plants keeping the gas share at the $10 \%$ level and phasing out coal.

In the gas market, the development until 2050 reflects that the demand by power plants reduces to $0 \%$ until 2050 in the 40\%DEF and 80\%GREEN scenarios for an average reference hour. In the $80 \%$ DEF scenario, the share of electricity demand in the natural gas market increases until 2050 due to an increase in the absolute gas fired generation output and a decline in overall gas demand. Interestingly, this indicates a reduction of demand by households (essentially for space heating) suggested by PRIMES.

The domestic production within Europe, including Norway, declines to about $70 \%$ of the 2010 values over the decades. In the $40 \%$ DEF case, the relatively stable total gas demand is fuelled by increasing pipeline imports from Russia and the Caspian region while LNG imports from Nigeria and the Middle East decline. In the $80 \%$ DEF scenario, the gas demand declines to about $75 \%$ of its 2010 values until $2050,13 \%$ of which are for the electricity market. The low demand levels lead to a corresponding price decrease and shift in the supply pattern. Gas demand declines stronger in Central and East Europe, reducing the need for Russian gas. South Europe has a slower demand decrease, keeping imports from Africa and via LNG more pronounced. This development is accelerated in the $80 \%$ GREEN case as the general demand decrease in the natural gas sector is combined with the decline of gas usage in the electricity sector. This leads to a sharp reduction of imports both via LNG and pipeline until 2050 while the demand level is reduced to about $55 \%$ of the 2010 values. These developments have an impact on the import dependence of Europe: whereas the 40\%DEF case has an import share of about $71 \%$ in 2050 , the $80 \%$ DEF has a share of about $65 \%$ and the $80 \%$ GREEN scenario a share of less than 50\%. Thus, the higher environmental targets lead to less import dependency due to an overall reduction of gas demand. Hence, infrastructure bottlenecks will be no issue in the natural gas network after 2020.

In sum, natural gas will only continue to play an important role in the energy system if CCS is delayed and/or nuclear power generation is phased out. Otherwise, coal with CCS has a cost-advantage over natural gas and renewables take increasingly large shares of electricity production. Our results confirm the mixed and ambiguous perspectives that others, like the European Energy Roadmap 2050 (EC, 
2011b) and the International Energy Agency (IEA, 2012c), see for natural gas. Clearly, the technology choices will play a crucial role, as indicated by the scenario selection of the EMF28 group (Knopf et al., 2013).

Figure 3: Price development, basic scenarios

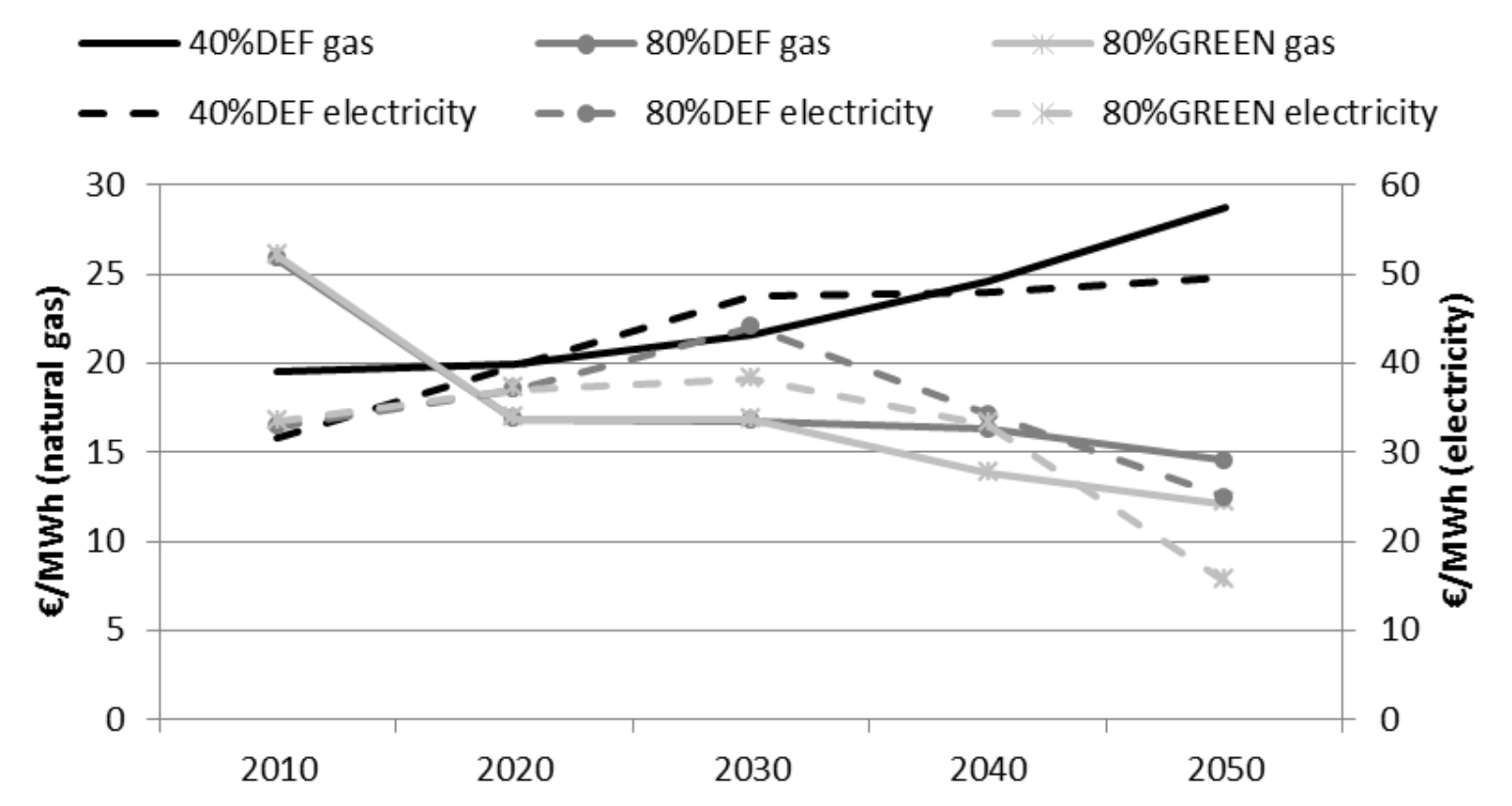

In summary, the basic results show that under average demand conditions network congestion is only a minor issue if the planned and projected pipeline, LNG, and transmission projects come online. The production and import pattern in the natural gas market remains similar to the setting currently observed with a high dependency on Russian and African gas, but this dependency can be reduced by increases in energy efficiency and RES generation. The production pattern in electricity depends on the emission price, RES capacities and nuclear restrictions while coal and gas fired plants are more or less fill-ins. 


\section{Congestion and Dispatch in the future European Electricity Market}

The basic market results are computed for average market conditions. While this is appropriate for the natural gas transmission network as storage and pipeline operation allow a relatively stable wholesale market level ${ }^{7}$, the same does not hold for the electricity market. Depending on demand conditions and RES availability, the actual dispatch can vary heavily between hours and thereby lead to different power flows, locational prices, and network utilization patterns. To capture those aspects in the following, we present a scenario analysis addressing peak demand and RES input variations. The analysis is carried out for 2010,2030 and 2050 to derive the general trends. ${ }^{8}$

\subsection{Impact of peak load conditions}

Electricity markets follow a daily demand pattern, with the highest demand usually around noon and in the evening and a significantly lower night-time demand. The peak demand hours can lead to an aggravation of congestion in the network. We therefore focus on such a peak setting to analyze the resulting price differences in Europe. We increase the demand level by $30 \%$ while keeping the same linear demand functionality as in the basic EMF scenarios.

Not surprisingly, the demand increase during peak times leads to a higher price level. In 2010, we observe an about 23\% higher price in all three scenarios. However, in 2030 and 2050, the price increase is more pronounced in the $80 \%$ DEF/GREEN scenarios (Table 3). This is a result of the different RES shares in the scenarios. As RES generation cannot be ramped up when demand increases, any increase needs to be covered by conventional units. In the 40\%DEF scenario, conventional units already cover a large share of demand under average conditions and consequently set market prices in most regions. During peak conditions, this setting does not change drastically. On the contrary, in the $80 \% \mathrm{DEF} / \mathrm{GREEN}$ scenarios, the demand increase requires to ramp up conventional units in regions that could be satisfied with RES and nuclear generation under average conditions; consequently the price increase is more pronounced. Nevertheless, the overall price level in the $80 \%$ DEF/GREEN scenarios is still lower under peak conditions in 2030 and 2050 than in the 40\%DEF scenario.

\footnotetext{
${ }^{7}$ On the distribution level, the actual hourly gas demand does have significant impacts on network utilization though. However, we limit our analysis here to the high-pressure long-distance transmission network.

${ }^{8}$ The results are obtained by using the simulated natural gas market prices as fuel input prices for the electricity market model.
} 
These aspects also translate into the overall network congestion level. Especially in 2050, the RESbased $80 \%$ DEF/GREEN scenarios show a higher congestion rent in the system than the more fossil based $40 \%$ DEF scenario, despite the about $40 \%$ lower price level. This is due to the fact that the network eventually limits the exchange between regions with excess RES supply and "import dependent" regions that need to switch to local conventional plants (Figure 4).

The high share of fossil generation also sets the congestion development in the 2010 cases. As peak demand requires a ramp up of local fossil plants and RES and nuclear plants are already at their maximum output, the price in each region is equalized and thereby reduces the actual dependence on import and export and the congestion rent. At the same time, the overall price level increases.

Figure 4: Peak load price levels in 2050, 40\%DEF and $80 \%$ GREEN
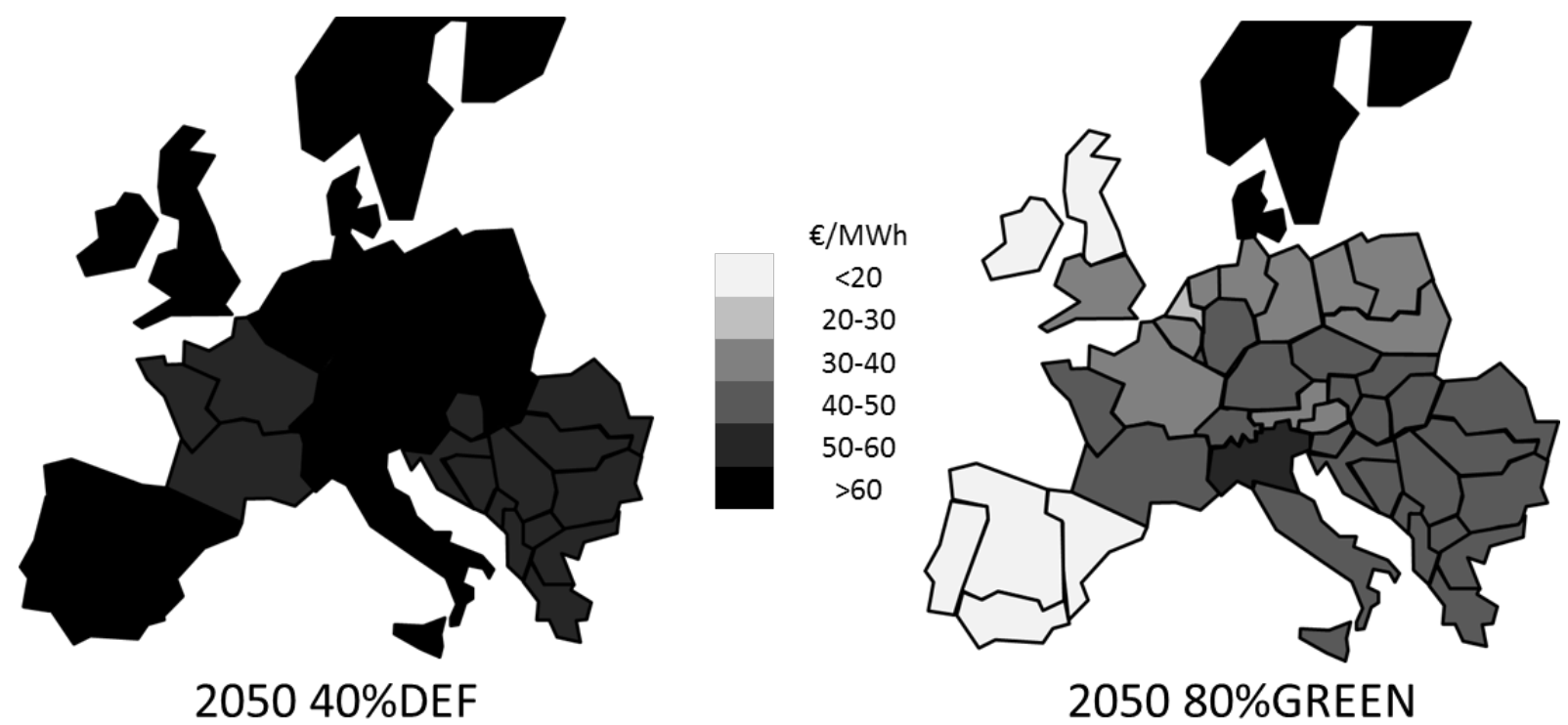

\subsection{Impact of high RES injection}

Similar to the load (demand) dependence, the availability of RES generation also has a significant impact on plant dispatch and network conditions. We focus on the influence of intermittent solar and wind production since biomass normally provides a base load profile. The two test cases represent a 
high wind and solar input setting respectively, while demand and all other input parameters are kept at prior levels. $^{9}$

Due to the merit order effect the resulting market prices in case of high RES input are lower compared to the average market conditions (compare Table 2 and Table 4). As the wind capacities are larger than the solar capacities, the impact of a high wind case on market prices is larger. And since the 80\%DEF/GREEN scenarios have an overall larger increase of RES capacities compared to the $40 \%$ DEF scenario, the impact of high RES availability is also more pronounced in those scenarios.

A higher RES input also leads to a higher congestion rent in the system, as the geographically diverse input cannot be equalized within Europe, leading to RES induced low price regions versus high price regions depending on fossil generation. The exceptions are the 2010 scenarios, which show a slight decrease in congestion rent, and 2050 in the $80 \%$ GREEN case. In 2010, the RES share is still rather moderate and an increase in the availability helps to reduce import requirements for the high price regions. In the $80 \%$ GREEN case in 2050 , the share of RES is basically $100 \%$ and thereby all market prices are reduced to zero, which annihilates the potential to pay any congestion rents although there are still lines at their capacity limit.

This case also highlights the 'oversupply' in the case of high RES availability in the 80\%DEF/GREEN scenarios in the long run. Given the available capacities in both RES cases, a share of the RES generation cannot be accommodated by the system. In the $80 \%$ GREEN case, this is the most pronounced with about $50 \%$ of the available wind and $30 \%$ of the solar generation not utilized in the example cases (Table 4). ${ }^{10}$

Given the higher installed wind capacities, it is not surprising to find that high wind availability leads to a more widespread price reduction than solar availability by 2030 (Figure 5). Due to its high wind share, the good geographical conditions for solar energy, and the limited transmission capacities towards France, the Iberian Peninsula is a low price region in nearly all cases. The remainder of Europe shows a more diverse picture. In the high wind settings, Western Europe faces a significant price reduction due to its offshore capacities whereas in high solar settings the North does not benefit as much.

\footnotetext{
${ }^{9}$ For the high wind input case, we assume an availability of onshore wind capacities of $70 \%$ and for offshore of $90 \%$ compared to $20-25 \%$ for onshore and $35-38 \%$ for offshore in the basic scenarios. For solar, we assume an availability of $60 \%$ for photovoltaic systems and $80 \%$ for CSP plants.

${ }^{10}$ The model does not include a feed-in guarantee for RES generation, thereby limiting the impact on network congestion compared to current regulations in some European countries (e.g. Germany).
} 


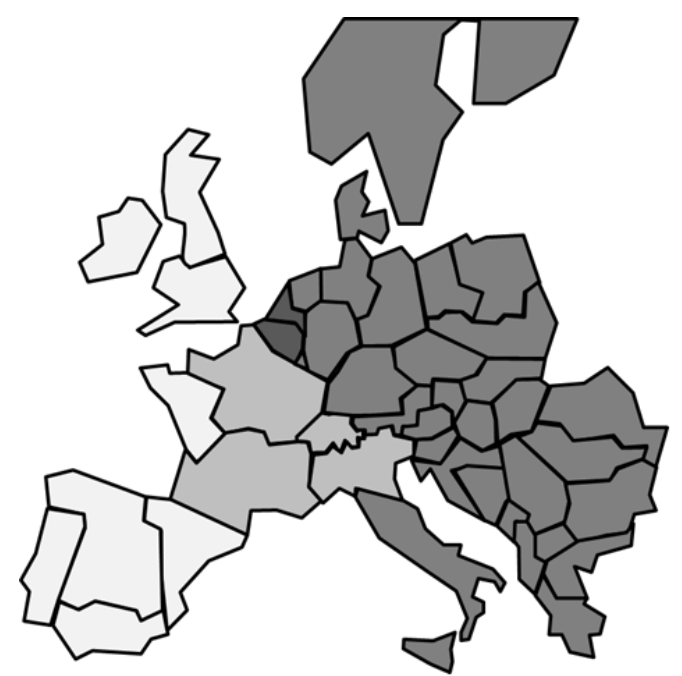

high wind

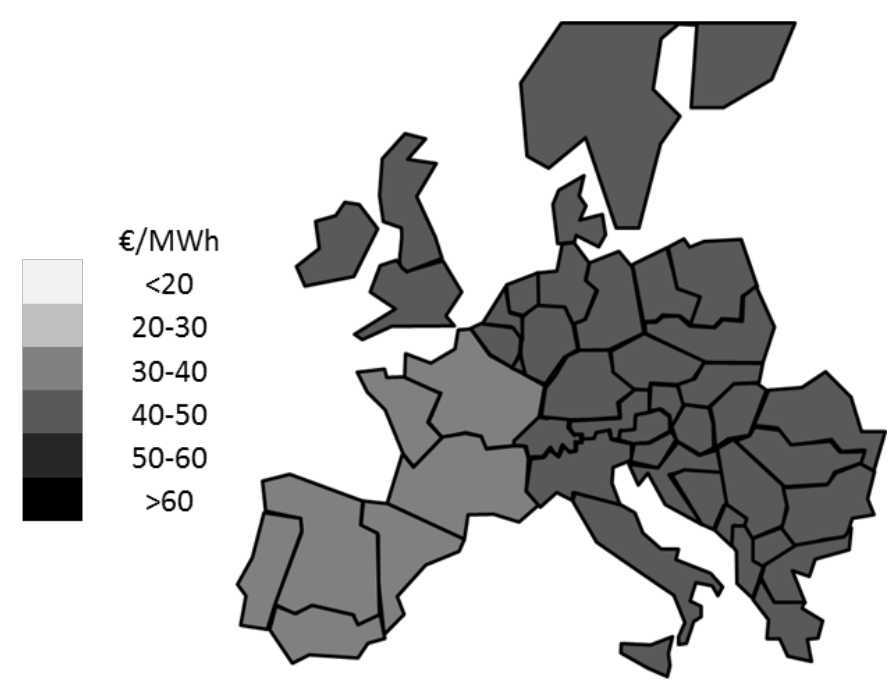

high solar

Examining the load flow patterns in more detail, some trends can be identified. The average load level of the transmission lines declines until 2050 for all scenarios because of network expansions, according to the TYNDP projects, and because of a higher share of local distributed generation. The wind cases show the highest load level, indicating the highest divergence between generation and demand regions. Finally, the peak load flow pattern is more or less an amplified version of the average load pattern for all scenarios. Congested lines are largely similar in all cases throughout the years.

Under high wind conditions, particularly lines in and around Germany, the UK, and between Spain and France experience bottlenecks. This holds for all scenarios. On the contrary, high solar injection has different impacts depending on the underlying scenario. In the $40 \%$ DEF scenario, the resulting congestion is similar to the average setting. This effect is largely based on the still relatively low share of solar based generation in relation to other types. Even in the 2050 case, only $30 \%$ of the RES injections come from solar in the high solar and about $70 \%$ of RES injections are from wind plants in the high wind case.

In the $80 \%$ DEF scenarios, the increase in solar capacities and their impact on power flows is higher. This leads to higher stress of lines in Italy in addition to the congestion on Spanish connections. Despite the even higher installed solar capacities in the $80 \%$ GREEN scenario in 2050, the impact on power flows is reduced. This is due to the higher share of $\mathrm{PV}$ in all regions that reduces local demand and the need for trade. 
Summarizing the results for the electricity market, we can largely confirm the expected developments: the increase of RES generation leads to a price reduction due to lower marginal costs, the planned network extensions underway favor price convergence, and finally, although congestion remains an issue on some links until 2050 it will neither be more problematic than what we can observe in the current market settings nor will it shift towards regions not already addressed in current extension plans.

\section{The Impact of the Gas Supply Interruptions on the Electricity System}

The basic results have already shown the interdependence of the European natural gas and electricity markets; e.g. the higher share of gas fired plants in the 80\%DEF scenario keeps gas prices above the 80\%GREEN levels. In addition to this long term effect on prices, more short term impacts can also influence the plant dispatch and resulting market prices. Given the import dependence of the European natural gas market, changes in the supply situation can feed back into the electricity market.

To test the robustness of the different scenarios with respect to external market shocks, we analyze two supply interruption cases: First, a supply stop from North African gas suppliers and second, a supply stop of Russian gas via the Ukraine and Belarus while direct connections to the EU remain open (i.e., Nordstream and South Stream). In the first shock, both the pipeline and the LNG exports are disrupted, simulating a similar situation than during the Arab Spring. This disruption will potentially have a strong effect on the South European importers, which rely on natural gas in their electricity generation and are hardly interconnected with the rest of the European natural gas network. ${ }^{11}$ The second shock reminds of the recurrent gas disputes between Russia and its transit countries Ukraine and Belarus (e.g. winter 2005/2006, winter 2008/2009). Given the strong dependence of East European countries on natural gas imports from Russia and the lack of possibilities to import from other sources, such a shock is likely to have a high impact in East Europe. However, after the gas disputes of the last years, the installation of reverse flow capacities that allow for West-East gas flows (opposite the traditional direction from Russia to the West) has increasingly been undertaken and is included in the network dataset starting from 2020 on, based on current ENTSO-G planning (ENTSO-G, 2011).

\footnotetext{
${ }^{11}$ See Lochner and Dieckhöhner (2012) for a disruption analysis of the North African suppliers focusing only on the natural gas sector.
} 
Overall, the two supply shocks produce similar market reactions in the 2010 model period. The Russian interruption is more severe, as the Nordstream and South Stream options are not yet available. This effect is smaller in subsequent years as Russia simply bypasses its transition countries via the Baltic Sea (Nordstream) and the Black Sea (South Stream). ${ }^{12}$ On the other hand, the North African supply shock leads to a stronger decline in gas fired electricity generation as Spain has a high share of gas plants that depend on imports from Africa.

In the future decades, the impact of the supply shock differs greatly between the three scenarios. In the $40 \% \mathrm{DEF}$ scenario, the supply shocks always lead to a significant price increase on the natural gas market while electricity prices only experience a slight increase (Table 5). The latter is due to the relatively low average share of gas fired plants in this scenario as coal units are more competitive, regardless of the gas supply condition. On the natural gas market, the demand decline is in the range of $3 \%$ to 5\%. Overall, the shortage of Russian gas is less severe in 2030 and 2050 than the African supply cut. This is due to the fact that gas supplies from Africa are largely consumed in South Europe and thus can hardly be replaced by other trade options beside LNG imports. As the latter are already heavily utilized under average conditions, a shortage of African supplies leaves South Europe with less gas to consume. On the other hand, the shortage of Russian gas via Belarus and the Ukraine leads to a reduction of availability in Eastern Europe which can partly be compensated by the reallocation of imports in Central Europe. By increasing LNG imports in the UK and shifting Norwegian gas for the UK towards continental Europe, using Germany as a transit hub towards East and South East Europe, a large share of the disruption can be compensated for.

In the $80 \% \mathrm{DEF}$ scenario, the share of gas plants in the electricity dispatch is the highest and the impact of a gas supply shortage on electricity markets is more distinctive than in the other two scenarios. In 2030 , the gas consumption by the electricity sector falls by $80 \%$ and the electricity price increases by about $20 \%$ (Table 5). On the other hand, the demand on the natural gas markets (for other usages like heating and transportation) slightly increases after the supply cuts, utilizing some of the freed up electricity gas demand. However, the combined natural gas demand declines. Again, the UK plays a crucial role: its large share of gas-fired power plants, coupled with its great LNG capacities, and import pipelines from Norway allow a flexible switching to the benefit of the continental European market. By

\footnotetext{
12 See Hubert and Ikonnikova (2011) for a game-theoretic analysis of the strategic value of the direct pipelines to the West for the Russian bargaining position. Our results confirm this analysis that Russia has a strong incentive not only to threat the unreliable transit countries with direct links but to actually implement them.
} 
freeing up LNG capacities (African case) or Norwegian imports (Russian case), they help to keep the impact on the European gas market moderate while their little interconnection with the continent limits feedback effects within the electricity network. In 2050, the overall gas demand has declined so far that a supply shock only induces small impacts in both markets.

In the $80 \%$ GREEN setting, Europe's gas demand is declining thereby reducing the impact of supply shocks. Similar to the $80 \%$ DEF scenario in 2030 , both shocks lead to a decrease of gas consumption in the electricity sector and an increase of gas demand by other users (Table 5). The sum of both is still $4 \%$ lower than without the shock, but the case again highlights the interdependence of both markets. Looking in more detail at the electricity market, we can observe a clear distinction between both interruption cases. In case of a shortage from Africa, gas fired plants in South Europe and large parts of Western and Central Europe are shut down while Southeast Europe is continuously supplied via South Stream, limiting the price impact in that region (Figure 6). In the Russian case, mainly East and Central Europe are affected where most of the reallocation of gas supplies from Norway and Nordstream takes place. The Iberian peninsula, as well as Southeast Europe, are only slightly affected since their traditional supply lines (Africa for the former, South Stream for the latter) are not interrupted and their interconnection towards Central Europe is limited (Figure 6).

Finally, in 2050, demand is so low and gas utilization in the electricity sector not relevant anymore and the existing infrastructure is capable to compensate both supply interruptions without significant price effects.

Figure 6: Electricity prices in dependence of gas supply shock in $2030,80 \%$ GREEN

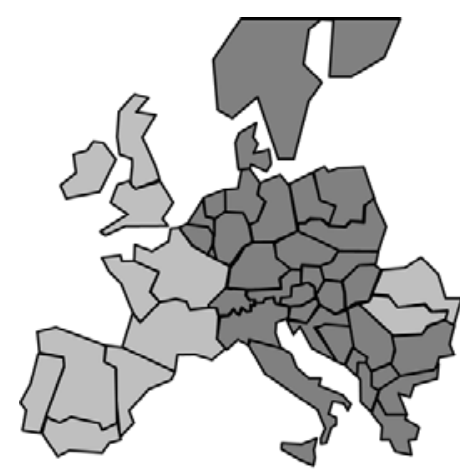

no shock

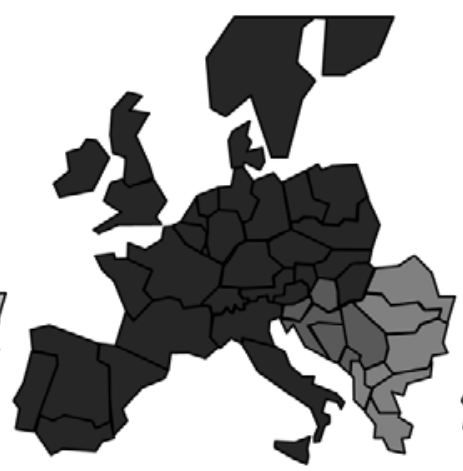

African supply shock

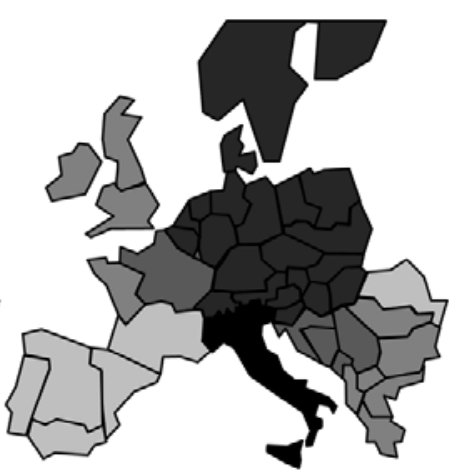

Russian supply shock
E/MWh 


\section{Conclusions}

The interdependence between natural gas and electricity markets is a major characteristic of current energy markets in all regions of the world. In this paper, we have applied a model that looks at natural gas and electricity simultaneously to analyze the EMF 28 scenarios for European decarbonization at the horizon 2030/2050. The modeling approach of "combining" energy network markets leads to insights that go beyond the traditional sector-specific approach.

Summarizing the model simulations of the development of the European gas and electricity markets, we can draw some general conclusions. First, the planned extensions of the existing network infrastructure, both in the electricity and gas system, will help to keep congestion on moderate levels on average. However, the timing of those extensions and the actual scale of the projects, especially in the electricity network, is uncertain. Experiences with current extension projects show long timeframes until the projects are finally realized (e.g. the Austrian extension of the $380 \mathrm{kV}$ ring) and increasing resistance to new projects (the NIMBY problem). So, if some of the assumed extensions are delayed or cancelled, then the congestion situation is likely to be more pronounced than in our simulations.

Second, although the European natural gas market will remain dependent on imports, the supply situation is rather comfortable and congestion plays only a minor role. This is especially true with the Nordstream pipeline which helps to increase the availability of gas in Central Europe and leads to an equalization of prices throughout Europe.

Third, the future European electricity supply tends to be less carbon-intensive. Regardless of the underlying scenario, if the 2050 emission targets are to be kept, fossil plants without CCS will phase out. However, even if CCS options are in place, the increasing share of RES will gradually push those to the margin. The crucial question is the timing of this process and not the eventual phasing out of conventional generation in the long run.

This development has a central impact on the gas market. In case of ambitious environmental policies and a fast RES deployment ( $80 \%$ GREEN), the role of gas is gradually minimized and frees up the gas infrastructure capacities for increased gas demand in other sectors, such as transportation. However, given stringent emission restrictions, these demand options may not be attractive and we may face excess capacity in the gas sector. If the environmental restrictions are only gradually tightened and RES deployment grows moderately (40\%DEF), fossil generation will play a more prominent role in the 
electricity market. Under those conditions, gas has to compete with coal if CCS technologies become available, nullifying the low emission advantage of gas. ${ }^{13}$ The shares of different fuels then strongly depend on the market prices of these fuels. Finally, in an in-between situation (80\%DEF), gas may indeed play an important role as the emission policy can lead to a lower total gas consumption and thereby lower gas prices in Europe. At the same time, the RES deployment is not fast enough to render fossil fuels obsolete until 2050. Given this framework, gas plants can benefit from low prices in Europe which may increase their share in generation compared to CCS coal plants.

In conclusion, we can say that the future development of natural gas in Europe will be determined by the general political framework while locational aspects due to the network structure play 'only' a secondary role. However, this general framework still provides a wide range of potential development paths.

Like all simulations, the presented results strongly depend on the underlying scenario assumptions and model restrictions. Those can lead to an underestimation of the role of gas in the electricity market and thereby an underestimation of the interaction. The time-static nature of the model and the average demand conditions simulated, in particular, can lead to an underestimation of gas demand in the electricity sector. This also includes the unit commitment and ramping restrictions of power plants. Similarly, the deterministic nature of the model neglects the high volatility of RES injection and a potential increase of balancing needs. All those aspects can lead to a higher influence of gas fired electricity production than anticipated in this paper.

The regional clustering in zones in both markets can also bias the results, as local congestion is neglected. Interestingly, we find a congestion effect of RES despite the high zonal aggregation level. Our results can be complemented by the nodal approach taken in Egerer et al. (2013) that investigate the same scenarios. Our model could be improved by using a nodal aggregation (electricity model) or at least further disaggregated zones (e.g. gas market zones in some countries). However, there are currently computational limits to a detailed disaggregation.

Similarly, the scaling of future generation capacities based on the current plant distribution has a significant impact on power flows, especially with a long term perspective of 40 years in which most plants will have to be replaced. Given future developments in congestion pricing, one can assume that

\footnotetext{
${ }^{13}$ The higher flexibility of gas plants is still an advantage but given the foreseeable increase in wind and solar forecast reliability this will become less important in day-ahead dispatch decision and be limited to balancing service.
} 
at least a part of newly installed conventional capacities will not be constructed at current locations but in high prices regions and thereby reduce system congestion. Regarding the resulting price levels, the assumption of perfect competition results in a potential downward bias and the obtained results represent a lower bound.

The gas market model is Europe-centered and neglects interactions with the US and Asian gas markets. This can lead to a price underestimation (e.g. if LNG demand by Asia is strong) or an overestimation (e.g. if increasing shale gas from the US lowers global prices). Since the partial market representation lacks a cross-price elasticity between the fuels, the natural gas demand does not react directly to low electricity prices via end use fuel substitution and only captures the impact of changes in the dispatch of gas fired power plants. Price changes due to variations in the consumption of coal are also not included, which could lead to a further demand decrease or increase in the natural gas sector. Finally, the emission permit price is exogenous to the model. Thus, resulting plant dispatch decisions have no feedback effect on the price and investments are externally defined and do not react to potential price changes due to changes in prices or dispatch. Future research should address all the methodological issues mentioned. 


\section{References}

Abrell, J., Weigt, H. (2012): Combining Energy Networks. Networks and Spatial Economics 12, 377401.

Arnold, M., Andersson, G. (2008): Decomposed electricity and natural gas optimal power flow, in: 16th Power Systems Computation Conference (PSCC 08), Glasgow, Scotland.

Brooke A., Kendrick D., Meeraus A. (2008): GAMS a user's guide. GAMS Development Cooperation, Washington.

Capros P., Georgakopoulos P., Van Regemorter D., Proost S., Schmidt C. (1997): The GEM-E3 general equilibrium of the European union. Economic and Financial Modeling. 21-160.

Capros, P. (2010): PRIMES Model Description, URL:

http://www.e3mlab.ntua.gr/e3mlab/index.php?option=com content\&view=category\&id=35\%3Aprim es\&ltemid=80\&layout=default\&lang=en; accessed: 30.01.2013.

EC (2011a): Energy Roadmap 2050. COM(2011) 885 final. COMMUNICATION FROM THE COMMISSION TO THE EUROPEAN PARLIAMENT, THE COUNCIL, THE EUROPEAN ECONOMIC AND SOCIAL COMMITTEE AND THE COMMITTEE OF THE REGIONS. Brussels.

EC (2011b): Energy Roadmap 2050: Impact Assessment, Part 2/2 (No. SEC(2011) 1565), COMMISSION STAFF WORKING PAPER. Brussels.

EC (2012): DG Energy, Quarterly Report on European Electricity Markets, 5 (1).

ECF (2011): Power Perspectives 2030 On the road to a decarbonised power sector. Power 1-85.

Egerer, J., Von Hirschhausen, C., Kunz, F. (2012): Planning the Offshore North and Baltic Sea Grid Technical and Socio-economic Analysis of Different Pathways. Electricity Markets Working Papers No. 47.

Egerer, J. Gerbaulet, C., Lorenz, C. (2013): European Electricity Grid Infrastructure Expansion in a 2050 Context. DIW Discussion Paper 1299.

Egging, R., Gabriel, S.A., Holz, F., Zhuang, J. (2008): A Complementarity Model for the European Natural Gas Market. Energy Policy 36 (7), pp. 2385-2414.

Egging, R., Holz, F., Gabriel, S.A. (2010): The World Gas Model: . A Multi-Period Mixed Complementarity Model for the Global Natural Gas Market. Energy 35, 4016-4029

ENTSO-E (2011): ENTSO-E Grid Map. ENTSO-E, Brussels.

ENTSO-E (2012a): 10-Year Network Development Plan 2012. ENTSO-E, Brussels.

ENTSO-E (2012b): Consumption Data. ENTSO-E, Brussels. https://www.entsoe.eu/data/dataportal/consumption/

ENTSO-G (2010): Transmission Capacity Map 2010 (Capacities at cross-border points on the primary market). June 2010. Available online at http://www.entsog.eu/maps/transmission-capacitymap/2010 (last visited on January 31, 2013). ENTSO-G, Brussels.

ENTSO-G (2011): Ten-Year Network Development Plan 2011-2020. ENTSO-G, Brussels.

ENTSO-G (2012): Transmission Capacity Map 2012 (Capacities at cross-border points on the primary market). May 2012. Available online at http://www.entsog.eu/maps/transmission-capacity-map (last visited on January 31, 2013). ENTSO-G, Brussels.

ESPON (2010): ReRisk - Regions at Risk of Energy Poverty. Luxemburg. 
EU, 2004: Council Directive 2004/67/EC of 26 April 2004 concerning measures to safeguard security of natural gas supply.

EU, 2006: Decision No 1364/2006/EC of the European Parliament and of the Council of 6 September 2006 laying down guidelines for trans-European energy networks and repealing Decision 96/391/EC and Decision No 1229/2003/EC.

EU, 2009: Regulation (EC) No 663/2009 of the European Parliament and of the Council of 13 July 2009 establishing a programme to aid economic recovery by granting Community financial assistance to projects in the field of energy.

Haller, M., Ludig, S., Bauer, N. (2012): Decarbonization scenarios for the EU and MENA power system: Considering spatial distribution and short term dynamics of renewable generation. Energy Policy 47 , pp. 282-290.

Ferris, M.C., Munson T.S. (2000): Complementarity problems in GAMS and the path solver. Journal of Economic Dynamics and Control 24(2),165-188

Hobbs, B.E. (2001): Linear complementarity models of Nash-Cournot competition in bilateral and POOLCO power markets. IEEE Transactions on Power Systems 16, 194-202.

Hubert, F. and Ikonnikova, S., 2011: Strategic Investments and Multilateral Bargaining in the Eurasian Gas Supply Network: A Shapley value analysis, The Journal of Industrial Economics, 59 (1), 85-116.

IEA (2012a): Natural Gas Information 2012. OECD, Paris.

IEA (2012b): Medium-Term Gas Market Report 2012. OECD, Paris.

IEA (2012c): World Energy Outlook 2012. OECD, Paris.

Institute of Prospective Technology Studies (IPTS) (2010): PROSPECTIVE OUTLOOK

ON LONG-TERM ENERGY SYSTEMS Poles model manual, URL:

http://ipts.jrc.ec.europa.eu/activities/energy-and-transport/documents/POLESdescription.pdf; accessed: 30.01 .2013$.

Knopf, B., Chen, Y.-H-H., De Cian, E., Förster, H., Kanudia, A., Karkatsouli, I., Keppo, I., Koljonen, T., Schumacher, K., van Vuuren, D.P. (2013): Beyond 2020 - Strategies and costs for transforming the European energy system. Mimeo.

Leuthold, F., Weigt, H., Hirschhausen, C. von (2012): A Large-Scale Spatial Optimization Model of the European Electricity Market. Networks and Spatial Economics 12, 75-107.

Lochner, S., Dieckhöhner, C. (2012): Civil unrest in North Africa—Risks for natural gas supply? Energy Policy 45, 167-175.

Möst, D., Perlwitz, H. (2009): Prospects of gas supply until 2020 in Europe and its relevance for the power sector in the context of emission trading. Energy 34, pp. 1510-1522

Neuhoff, K., Ehrenmann, A., Butler, L., Cust, J., Hoexter, H., Keats, K., Kreczko, A., Sinden, G. (2008): Space and time: Wind in an investment planning model. Energy Economics 30 (4), pp. 1990-2008.

Paltsev S, Reilly JM, Jacoby HD, Eckaus RS, McFarland J, Sarofim M, Asadoorian M, Babiker M (2005): The MIT Emission Prediction and Policy Analysis (EPPA) model: version 4. MIT Joint program on the science and policy of global change report

Platts (2011): World Electric Power Plants Database. URL http://www.platts.com/Products/worldelectricpowerplantsdatabase 
Schweppe, F.C., Caraminis, M.C., Tabors, R.D., Bohn, R.E. (1988): Spot Pricing of Electricity. Boston: Kluwer Academic Publishers.

Sotkiewicz, P.M. (2012): Value of conventional fossil generation in PJM considering renewable portfolio standards: A look into the future, in: 2012 IEEE Power and Energy Society General Meeting. Presented at the 2012 IEEE Power and Energy Society General Meeting, pp. 1 -5.

SRU (2010): 100\% erneuerbare Stromversorgung bis 2050: klimaverträglich, sicher, bezahlbar. Berlin: SRU.

Unsihuay, C., Lima, J.W.M., De Souza, A.C.Z. (2007): Modeling the Integrated Natural Gas and Electricity Optimal Power Flow, in: IEEE Power Engineering Society General Meeting, 2007. Presented at the IEEE Power Engineering Society General Meeting, 2007, pp. $1-7$. 


\section{Appendix}

Table 1: Basic market results, natural gas

\begin{tabular}{|c|c|c|c|c|c|}
\hline & 2010 & 2020 & 2030 & 2040 & 2050 \\
\hline \multicolumn{6}{|l|}{ 40\%DEF } \\
\hline Price [€/MWh] & 19.58 & 19.91 & 21.57 & 24.60 & 28.72 \\
\hline Gas Demand [GW] & 801.10 & 834.96 & 813.67 & 798.14 & 780.46 \\
\hline Elec. Gas Demand [GW] & 61.32 & 79.87 & 24.80 & 17.43 & 11.31 \\
\hline Pipeline Import [GW] & 319.52 & 367.46 & 390.16 & 402.64 & 425.10 \\
\hline LNG Import [GW] & 204.93 & 259.53 & 191.87 & 171.22 & 137.51 \\
\hline EU Production [GW] & 337.97 & 287.82 & 256.44 & 241.70 & 229.15 \\
\hline \multicolumn{6}{|l|}{ 80\%DEF } \\
\hline Price [€/MWh] & 25.89 & 16.85 & 16.76 & 16.30 & 14.57 \\
\hline Gas Demand [GW] & 820.63 & 789.38 & 762.21 & 707.61 & 572.40 \\
\hline Elec. Gas Demand [GW] & 47.45 & 91.45 & 83.99 & 82.80 & 87.61 \\
\hline Pipeline Import [GW] & 321.60 & 361.25 & 375.84 & 347.36 & 253.95 \\
\hline LNG Import [GW] & 208.42 & 228.18 & 207.34 & 199.98 & 177.30 \\
\hline EU Production [GW] & 338.06 & 291.40 & 263.01 & 243.07 & 228.77 \\
\hline \multicolumn{6}{|l|}{$80 \%$ GREEN } \\
\hline Price [€/MWh] & 26.01 & 16.89 & 16.82 & 13.84 & 12.13 \\
\hline Gas Demand [GW] & 821.43 & 791.61 & 733.63 & 637.60 & 481.17 \\
\hline Elec. Gas Demand [GW] & 47.56 & 93.22 & 82.75 & 16.39 & 1.74 \\
\hline Pipeline Import [GW] & 322.13 & 364.10 & 357.35 & 242.13 & 161.16 \\
\hline LNG Import [GW] & 208.80 & 227.78 & 198.49 & 166.45 & 87.88 \\
\hline EU Production [GW] & 338.06 & 292.95 & 260.54 & 245.41 & 233.87 \\
\hline
\end{tabular}


Table 2: Basic market results, electricity

\begin{tabular}{|c|c|c|c|c|c|}
\hline & 2010 & 2020 & 2030 & 2040 & 2050 \\
\hline \multicolumn{6}{|l|}{ 40\%DEF } \\
\hline Price [€/MWh] & 31.60 & 39.79 & 47.45 & 48.00 & 49.68 \\
\hline Demand [GW] & 323.27 & 359.24 & 360.39 & 383.13 & 408.76 \\
\hline Congestion Rent [mn/h] & 0.29 & 0.12 & 0.02 & 0.23 & 0.19 \\
\hline RES Share & $29 \%$ & $44 \%$ & $56 \%$ & $59 \%$ & $59 \%$ \\
\hline Gas Share & $10 \%$ & $12 \%$ & $4 \%$ & $2 \%$ & $1 \%$ \\
\hline Coal Share & $29 \%$ & $15 \%$ & $12 \%$ & $10 \%$ & $10 \%$ \\
\hline Nuclear Share & $32 \%$ & $28 \%$ & $28 \%$ & $29 \%$ & $30 \%$ \\
\hline CCS Share of fos. Gen. & $0 \%$ & $2 \%$ & $11 \%$ & $98 \%$ & $98 \%$ \\
\hline \multicolumn{6}{|l|}{ 80\%DEF } \\
\hline Price [€/MWh] & 32.91 & 37.09 & 44.14 & 34.26 & 24.91 \\
\hline Demand [GW] & 324.76 & 371.43 & 369.62 & 445.56 & 483.67 \\
\hline Congestion Rent [mn/h] & 0.48 & 0.10 & 0.04 & 0.00 & 0.07 \\
\hline RES Share & $30 \%$ & $46 \%$ & $63 \%$ & $67 \%$ & $71 \%$ \\
\hline Gas Share & $8 \%$ & $14 \%$ & $13 \%$ & $10 \%$ & $10 \%$ \\
\hline Coal Share & $28 \%$ & $13 \%$ & $0 \%$ & $3 \%$ & $3 \%$ \\
\hline Nuclear Share & $34 \%$ & $27 \%$ & $23 \%$ & $19 \%$ & $17 \%$ \\
\hline CCS Share of fos. Gen. & $0 \%$ & $2 \%$ & $3 \%$ & $100 \%$ & $100 \%$ \\
\hline \multicolumn{6}{|l|}{ 80\%GREEN } \\
\hline Price [€/MWh] & 33.38 & 37.04 & 38.20 & 33.07 & 15.56 \\
\hline Demand [GW] & 323.49 & 370.92 & 392.70 & 452.80 & 502.14 \\
\hline Congestion Rent [mn/h] & 0.50 & 0.10 & 0.05 & 0.14 & 0.60 \\
\hline RES Share & $30 \%$ & $46 \%$ & $67 \%$ & $85 \%$ & $94 \%$ \\
\hline Gas Share & $8 \%$ & $14 \%$ & $12 \%$ & $2 \%$ & $0 \%$ \\
\hline Coal Share & $29 \%$ & $13 \%$ & $2 \%$ & $1 \%$ & $1 \%$ \\
\hline Nuclear Share & $33 \%$ & $27 \%$ & $18 \%$ & $12 \%$ & $5 \%$ \\
\hline CCS Share of fos. Gen. & $0 \%$ & $2 \%$ & $2 \%$ & $100 \%$ & $100 \%$ \\
\hline
\end{tabular}

Table 3: Load impact on electricity markets

\begin{tabular}{|c|c|c|c|c|c|c|}
\hline \multirow[b]{2}{*}{ Load Condition: } & \multicolumn{2}{|c|}{ 40\%DEF } & \multicolumn{2}{|c|}{ 80\%DEF } & \multicolumn{2}{|c|}{ 80\%GREEN } \\
\hline & Average & Peak & Average & Peak & Average & Peak \\
\hline \multicolumn{7}{|l|}{ 2010: } \\
\hline Price [€/MWh] & 31.60 & 38.87 & 32.91 & 40.83 & 33.38 & 41.16 \\
\hline Demand [GW] & 323.27 & 399.65 & 324.76 & 398.48 & 323.49 & 397.86 \\
\hline Congestion Rent [mn/h] & 0.29 & 0.20 & 0.48 & 0.36 & 0.50 & 0.35 \\
\hline Conventional/RES-Ratio & $71 / 29$ & $77 / 23$ & $70 / 30$ & $76 / 24$ & $70 / 30$ & $76 / 24$ \\
\hline \multicolumn{7}{|l|}{ 2030: } \\
\hline Price [€/MWh] & 47.45 & 56.59 & 44.14 & 55.95 & 38.20 & 48.30 \\
\hline Demand [GW] & 360.39 & 457.89 & 369.62 & 454.75 & 392.70 & 482.57 \\
\hline Congestion Rent $[\mathrm{mn} / \mathrm{h}]$ & 0.02 & 0.21 & 0.04 & 0.24 & 0.05 & 0.13 \\
\hline Conventional/RES-Ratio & $44 / 56$ & $56 / 44$ & $36 / 63$ & $48 / 52$ & $32 / 67$ & $46 / 54$ \\
\hline \multicolumn{7}{|l|}{ 2050: } \\
\hline Price [€/MWh] & 49.68 & 63.55 & 24.91 & 36.35 & 15.56 & 37.25 \\
\hline Demand [GW] & 408.76 & 499.88 & 483.67 & 577.55 & 502.14 & 568.11 \\
\hline Congestion Rent $[\mathrm{mn} / \mathrm{h}]$ & 0.19 & 0.42 & 0.07 & 0.42 & 0.60 & 1.63 \\
\hline Conventional/RES-Ratio & $41 / 59$ & $52 / 48$ & $30 / 71$ & $40 / 60$ & $6 / 94$ & $14 / 86$ \\
\hline
\end{tabular}


Table 4: RES impact on electricity markets

\begin{tabular}{|c|c|c|c|c|c|c|}
\hline \multirow[b]{2}{*}{ High RES Injection: } & \multicolumn{2}{|c|}{$40 \% \mathrm{DEF}$} & \multicolumn{2}{|c|}{ 80\%DEF } & \multicolumn{2}{|c|}{ 80\%GREEN } \\
\hline & Wind & Solar & Wind & Solar & Wind & Solar \\
\hline \multicolumn{7}{|l|}{ 2010: } \\
\hline Price [€/MWh] & 29.66 & 31.05 & 30.80 & 32.35 & 30.96 & 32.94 \\
\hline Congestion Rent $[\mathrm{mn} / \mathrm{h}]$ & 0.29 & 0.28 & 0.36 & 0.46 & 0.37 & 0.49 \\
\hline Un-dispatched RES & $0 \%$ & $0 \%$ & $0 \%$ & $0 \%$ & $0 \%$ & $0 \%$ \\
\hline \multicolumn{7}{|l|}{ 2030: } \\
\hline Price [€/MWh] & 26.69 & 43.77 & 17.44 & 39.60 & 11.45 & 29.64 \\
\hline Congestion Rent $[\mathrm{mn} / \mathrm{h}]$ & 0.45 & 0.19 & 0.60 & 0.32 & 0.85 & 0.23 \\
\hline Un-dispatched RES & $0 \%$ & $0 \%$ & $0 \%$ & $0 \%$ & $4 \%$ & $0 \%$ \\
\hline \multicolumn{7}{|l|}{ 2050: } \\
\hline Price [€/MWh] & 25.04 & 39.38 & 7.37 & 12.17 & 0.00 & 1.36 \\
\hline Congestion Rent $[\mathrm{mn} / \mathrm{h}]$ & 0.48 & 0.40 & 0.72 & 0.35 & 0.00 & 0.08 \\
\hline Un-dispatched RES & $0 \%$ & $0 \%$ & $13 \%$ & $3 \%$ & $48 \%$ & $29 \%$ \\
\hline
\end{tabular}

Table 5: Impact of shocks in the natural gas market

\begin{tabular}{|c|c|c|c|c|c|c|c|c|c|}
\hline \multirow[b]{2}{*}{ Gas Shortage: } & \multicolumn{3}{|c|}{ 40\%DEF } & \multicolumn{3}{|c|}{$80 \% D E F$} & \multicolumn{3}{|c|}{ 80\%GREEN } \\
\hline & None & Africa & Russia & None & Africa & Russia & None & Africa & Russia \\
\hline \multicolumn{10}{|l|}{$2010:$} \\
\hline Gas Price [€/MWh] & 19.6 & 25.5 & 32.1 & 25.9 & 34.8 & 43.8 & 26.0 & 35.0 & 44.0 \\
\hline Gas Demand [GW] & 801.1 & 746.6 & 645.0 & 820.6 & 750.5 & 649.3 & 821.4 & 750.3 & 648.7 \\
\hline El. Gas Dem. [GW] & 61.3 & 6.4 & 35.4 & 47.4 & 6.6 & 36.5 & 47.6 & 6.9 & 34.3 \\
\hline Elec. Price [€/MWh] & 31.6 & 36.6 & 34.8 & 32.9 & 36.1 & 34.3 & 33.4 & 36.4 & 34.6 \\
\hline \multicolumn{10}{|l|}{ 2030: } \\
\hline Gas Price [€/MWh] & 21.6 & 31.8 & 28.9 & 16.7 & 22.7 & 23.6 & 16.8 & 19.3 & 19.5 \\
\hline Gas Demand [GW] & 813.7 & 777.4 & 791.1 & 762.2 & 774.4 & 769.5 & 733.6 & 758.7 & 749.5 \\
\hline El. Gas Dem. [GW] & 24.8 & 9.7 & 8.9 & 84.0 & 15.7 & 15.7 & 82.7 & 24.1 & 36.7 \\
\hline Elec. Price [€/MWh] & 47.5 & 49.8 & 49.9 & 44.1 & 51.9 & 51.6 & 38.2 & 42.3 & 41.1 \\
\hline \multicolumn{10}{|l|}{ 2050: } \\
\hline Gas Price [€/MWh] & 28.7 & 40.8 & 41.5 & 14.6 & 15.3 & 15.3 & 12.1 & 12.4 & 12.2 \\
\hline Gas Demand [GW] & 780.5 & 748.0 & 750.0 & 572.4 & 573.8 & 578.8 & 481.2 & 480.3 & 480.9 \\
\hline El. Gas Dem. [GW] & 11.3 & 3.0 & 2.46 & 87.6 & 79.8 & 67.0 & 1.7 & 1.7 & 1.7 \\
\hline Elec. Price [€/MWh] & 49.7 & 50.6 & 50.6 & 24.9 & 25.9 & 27.3 & 15.6 & 15.6 & 15.6 \\
\hline
\end{tabular}

